\title{
Facing acute neuromuscular diseases during COVID-19 pandemic: focus on Guillain-Barré syndrome
}

\author{
Giuliana Galassi ${ }^{1} \cdot$ Alessandro Marchioni ${ }^{2}$
}

Received: 30 April 2020 / Accepted: 29 June 2020 / Published online: 21 July 2020

(c) Belgian Neurological Society 2020

\begin{abstract}
In December 2019, a cluster of cases with 2019 Novel Coronavirus pneumonia from Wuhan, China, aroused worldwide concern due to an escalating outbreak in all the countries in the world. Coronavirus belongs to a family of single-stranded RNA viruses, which includes severe acute respiratory syndrome (SARS-CoV) and Middle East respiratory syndrome (MERS$\mathrm{CoV}$ ), that have caused human epidemics with high fatality. The spectrum of the novel coronavirus disease (SARS-Co-2 or COVID-19) ranges from asymptomatic infections to fatal pneumonia, and differs from other viral pulmonary infections. MERS-CoV is known to be potentially neuroinvasive. Extensive reports from China documented central and peripheral nervous system involvement in patients with COVID-19, and identified in angiotensin converting enzyme2 (ACE2), which is present in multiple human organs, the functional receptor for this virus. Guillain-Barré syndrome (GBS) has recently been associated to COVID-19 rising concern among physicians. This review summarizes the current state of knowledge on GBS during or after COVID-19 infection, attempting to clarify the pathophysiology of the associated respiratory dysfunction and failure.
\end{abstract}

Keywords Guillain-Barré syndrome $\cdot$ COVID-19 $\cdot$ MERS-CoV $\cdot$ SARS-CoV $\cdot$ Acute respiratory distress (ARDS) - Acute axonal $\cdot$ Demyelinating neuropathy

$\begin{array}{ll}\text { Abbreviations } \\ \text { ACE2 } & \begin{array}{l}\text { Angiotensin converting enzyme 2 } \\ \text { Acute respiratory distress syndrome }\end{array} \\ \text { ARDS } & \begin{array}{l}\text { Acute inflammatory demyelinating } \\ \text { AIDP }\end{array} \\ \text { neuropathy }\end{array}$

Giuliana Galassi

giulianagalassi@alice.it

1 Department of Biomedical, Metabolic and Neural Sciences, Neurology Unit, Via P Giardini, 1350, 41126 Modena, Italy

2 Respiratory Disease Unit, Department of Medical and Surgical Sciences, Azienda Ospedaliero Universitaria, Via del Pozzo, 71 Modena, Italy

\section{SARS-CoV Severe acute respiratory syndrome coronavirus}

TMPRSS2 Transmembrane protein serine protease 2

\section{Introduction}

In December 2019, a cluster of cases with a novel Coronavirus pneumonia (SARS-CoV-2, i.e., 2019-nCov) rapidly spread from Wuhan, Hubei, China, becoming a global health threat [1-7]. While several human coronaviruses are associated with mild respiratory symptoms, the recently experienced types of coronavirus, including Severe Acute Respiratory Syndrome (SARS-CoV) in 2003 and Middle East Respiratory Syndrome (MERS-CoV) in 2012, have caused human epidemics and high fatality $[10,15,16]$. Although the current SARS-CoV-2 shares 79\% of its genome with SARS-CoV, it appears to be much more transmissible [1-3, $6,7,11-14]$. SARS-CoV-2 infections have been associated with acute neurological syndromes which need special attention as they could be overshadowed by the severity of pulmonary and cardiological manifestations [12, 13, 17-25]. 
Several authors highlighted the key role of monitoring the occurrence of neuromuscular disorders (NMD) such as Guillain-Barré syndrome (GBS), myositis, critically illness myopathy and neuropathy (CIP/CIM) during SARSCoV-2 infection [27-30]. Guidon et al. [26] highlighted the need for neurologists to be vigilant during the pandemic for the risk of infection exacerbating known conditions due to immunosuppressive and immunomodulatory therapies. The purpose of this paper is to review the current knowledge about a potential life-threatening neuromuscular complication of SARS-CoV-2 such as GBS and to summarize the lung pathophysiological changes resulting from the overlap of respiratory muscle dysfunction due to GBS in the course of severe acute respiratory syndrome (ARDS) from coronavirus.

\section{History of the novel COVID-19 virus}

Coronaviruses are enveloped non-segmented positivesense RNA viruses belonging to the Coronaviridae family and the Nidoviridales order broadly distributed in humans and other mammals [1-7, 11-13]. Although most human coronavirus infections are mild, the epidemics of the two recent beta coronaviruses, i.e., SARS-CoV and MERS$\mathrm{CoV}$, caused more than 10,000 cases with mortality rates of $10 \%$ for SARS-CoV and 37\% for MERS-CoV [1-7]. Genomic analysis shows that SARS-CoV-2 is in the same betacoronavirus clade as MERS-CoV and SARS-CoV, and shares with SARS-CoV highly homological sequence and similar pathogenesis with pneumonia induced by SARSCoV or MERS-CoV [15]. Huang et al. [2] first described pneumonia associated in $29 \%$ of cases with ARDS requiring ICU admission for mechanical ventilation (MV) and oxygen therapy. ARDS could develop within 2 days with mortality rate rising quickly up to $15 \%[1-3,11-13]$. Huang et al. [2] detected by next-generation sequencing or real-time reverse-transcriptase-polymerase-chain-reaction (RT-PCR) methods the presence of 2019-nCoV (or SARSCoV-2) in respiratory specimens of 41 subjects with pneumonia. The complete genome of the 2019-nCoV virus was identified in January 2020 as a 29,903 bp single-stranded RNA (ss-RNA) coronavirus previously reported in bats in China. Huang et al. [2] showed that patients infected with 2019-nCoV during the acute phase of their illness develop a "cytokine storm" with high amounts of proinflammatory cytokines (i.e., IL1B, IL6, IL12, IFN $\gamma$ ) in serum associated with pulmonary inflammation and extensive lung damage $[2,4,14,19,20]$. Moreover, the severity of the "cytokine storm" was related with disease severity, as plasma levels of proinflammatory cytokines and TNF $\alpha$ were higher in ICU patients than in non-ICU patients [2-5].

\section{General survey on host virus interaction and neurotropic evidence of SARS-CoV-2}

The novel CoV-19, similar to SARS-CoV1 and MERSCoV, causes multiple systemic symptoms $[2-5,7,8$, 19, 31-35]. Like SARS-CoV1, SARS-CoV-2 cell entry depends on the binding to the metallopeptidase named angiotensin converting enzyme2 (ACE2). The transmembrane protein serine protease 2 (TMPRSS2) is also required for viral entry into cells $[9,15,19-25,32-35]$. ACE is richly expressed not only in lung pneumocytes type II, but also in vascular endothelium, cardiomyocytes, smooth muscle cells and enterocytes. COVID-19 might use a spike protein $\mathrm{S} 1$ that enables the attachment of the virion to the cell membrane by interacting with the receptor $[8,9]$. The presence of the virus in the blood may facilitate the interaction of the virus spike protein with ACE2 receptors expressed in the vascular endothelium, leading to vascular ruptures and bleeding.

The exact routes by which SARS-CoV and MERS$\mathrm{CoV}$ enter central nervous system (CNS) throughout the blood-brain barrier (BBB) is still unknown. It has been speculated that following the viremia, SARS-CoV-2 can infect monocytes, macrophages and endothelial cells to migrate through the $\mathrm{BBB}[8,14,20-23]$. Plausible pathways for dissemination could be hematogenous and lymphatic circulation, or via the cribriform plate of the ethmoid bone, close to the olfactory bulb [14, 15, 17, 19]. Experimental studies using transgenic mice revealed that coronaviruses, when given intranasally, enter the brain via the olfactory nerves and thereafter spread to the thalamus and brainstem [14]. Indeed, hypogeusia, hyposmia, hypopsia are clinical markers of COVID-19 infection [2-6, 19-21, 23]. Researchers detected SARS-CoV nucleic acid in the spinal fluid of patients with generalized seizures and viral antigens in the brainstem, in which the infected regions included the nucleus of the solitary tract and the nucleus ambiguus $[14,19,20]$. The nucleus of the solitary tract receives sensory information from mechanoand chemoreceptors in the lung, while the efferent fibers from the nucleus ambiguus and of the solitary tract provide innervation to airway smooth muscle, glands, and blood vessels. The damage in these connections could result in a dysfunction of the cardiorespiratory center in the brainstem.

\section{General survey on GBS triggers and phenotypes}

The potential involvement of the peripheral nervous system by COVID-19 has attracted considerable attention. Several authors at the time of this writing have described 
cases of neuromuscular disorders focusing on a possible relationship with SARS-CoV-2 infection. GBS is an acute, post-infectious humorally mediated disorder with rapidly progressive, usually monophasic course. Almost twothirds of adult patients develop neurological symptoms 2-4 weeks after infection [36-44]. The incidence of GBS is approximately $1-2$ cases per 100,000 people per year, increased in people aged 80 years and over, slightly more frequent in males than in females [38, 41-43]. There are two major subtypes, based on electrophysiological and pathological features, i.e., acute inflammatory demyelinating polyneuropathy (AIDP), and acute motor/sensorimotor axonal or demyelinating neuropathy (AMAN/AMSAN/ AMSAD) [36, 37, 41-43]. At present, a wide range of anti-nerve autoantibodies directed at proteins and glycolipids, including GM1, GM1b, GD1a, GalNAc-GD1a, and GQ1b, are considered responsible for immunopathology of AIDP, AMAN and Miller Fisher (MFS) syndrome [36, 37, 41, 44-47]. Albuminocytologic dissociation is reported in $2 / 3$ cases in the first week after onset of symptoms, and the frequency of anti-ganglioside antibodies is highly dependent on GBS subtype [38, 41]. In typical cases, GBS exhibits bilateral ascending weakness which starts in distal lower extremities, but the onset can happen proximally in legs or arms with a combination of cranial nerve involvement resulting in several clinically distinctive variants, formes frustes, and atypical cases with facial, oculomotor, or bulbar weakness, which might then extend to involve the limbs [36-38, 41, 42]. The frequency of these variant forms in part relates to the geographical area in which the disease is reported [36-38, 41, 42]. In addition to weakness, patients might initially have sensory signs, ataxia, and features of autonomic dysfunction [36-38, 41-43]. Respiratory insufficiency is a life-threatening manifestation that occurs in $20-30 \%$ of patients [48, 49]. Many different antecedent infections have been identified as triggers of GBS, but only for a few microorganisms an association has been shown in case-control studies [46-48]. Campylobacter jejuni ( $C$. jejuni) is the predominant antecedent infection, found in $25-50 \%$ of adult patients [38, 41]. The original rationale rising from animal models was that a molecular mimicry exists between specific microbial proteins and peripheral nerve glycolipids leading to an innocent bystander attack against the myelin or the axon [41, $46,47]$. Lipo-oligosaccharides on the $C$. jejuni outer membrane may elicit the production of antibodies that cross react with gangliosides on peripheral nerves [36, 37, 41]. Other pathogens associated with GBS are cytomegalovirus (CMV), Epstein-Barr, influenza A virus, Mycoplasma pneumoniae, Haemophilus influenzae [41, 46]. However, molecular mimicry has not been shown or proven in any pathogen besides $C$. jejuni [41].
Recently, epidemiological, virological and serological evidence has supported the causal relationship between Zika virus (ZIKV) infection and GBS in the Pacific Islands and the Americas [50-52]. In ZIKV, some authors observed neurologic onset immediately after the viral syndrome and speculated that a hyperacute immune response or direct viral neuropathic mechanism on Schwann cell and axonal structures might be effective. Pathogenesis of GBS in the course of ZIKV disease is currently unknown, but also an aberrant immune response through antigen-presenting cell activation of T-lymphocytes could be involved. Recent works by Lucchese et al. [52] found that there is a high peptide overlap between the ZIKV polyprotein and human proteins related to myelin and axon.

\section{Acute neuromuscular syndromes during coronavirus infections}

Tsai et al. [53] described four patients with neuromuscular disorders during SARS outbreak in Taiwan. The neurological onset in these patients was evident 3 weeks after the respiratory symptoms; two cases developed an acute motor predominant neuropathy, one case both myopathy and neuropathy, and the fourth developed a mild myopathy. As three patients received ICU care for multiple organ failure, these authors [53] cautiously considered the differential diagnosis with CIP and CIM.

Kim et al. [15] reported four patients infected with MERS-CoV who presented with neurological symptoms delayed by $2-3$ weeks from respiratory symptoms. The most interesting case of this series was a 55-year-old male who developed ARDS, septic shock and multiorgan dysfunction. When this patient was discharged from ICU, he exhibited external ophthalmoplegia, extremity weakness, ataxia and hyporeflexia diagnosed as Bickerstaff's brain stem encephalitis (BBE) overlapping GBS; the remaining three cases had either normal neurological examination or sensory symptoms and lower limb weakness with loss of deep reflexes.

Mao et al. [19] reported detailed neurologic manifestations in 214 hospitalized patients with the COVID-19 infection; among those, $24 \%$ had CNS signs, whereas $8.9 \%$ had peripheral nervous system signs, and $10 \%$ skeletal muscle involvement. Increased CK and LDH levels were especially high in cases with severe infection and with muscle symptoms [19]. Neurologic manifestations occurred early in the illness with median time to hospital admission of 1-2 days; moreover, patients with severe infections were older as compared to non-severe patients [19]. Beydon et al. [54] described a male with an autoimmune myositis as manifestation of SARS-CoV-2 infection who experienced sudden difficulty on waking, myalgias, proximal lower limb muscle weakness, lymphocytopenia, CK elevation at 25,384 IU/L 
and increased $\mathrm{C}$ reactive protein. Muscle MRI showed edema and focal enhancing lesions.

\section{GBS during SARS-CoV-2 infection}

At the time of this writing, at least 14 patients presenting GBS related to SARS-CoV-2 have been described [55-65]. Among those, the two cases reported by Gutiérrez-Ortiz et al. [59] exhibited a MFS variant and an isolated cranial polyneuritis, which might be considered an entity located at the interface between MFS and GBS. Other authors [66, 67] reported a rare "regional form" of GBS with bifacial symmetric weakness, limb paresthesias and sensory ataxia, similar to one of the patients described by Toscano et al. [56]. Dinkin et al. [60] reported a cranial neuropathy with abnormal MRI findings in two patients, one of whose showed optic nerve sheath enhancement suggestive of a viral leptomeningeal invasion.

Patients commonly experience prior viral illness either with fever or respiratory symptoms from 2 to 10 days before the onset of neurological signs. However, Zhao et al. [55] described a case of AIDP antedating by 7 days fever and respiratory symptoms, similar to the one reported by Ottaviani et al. [65] who developed neurological deficits overlapping those of SARS-CoV-2 infection.

More than $50 \%$ of patients exhibited electrophysiological features consistent with an acute demyelinating polyneuropathy; in contrast, only four patients had an axonal profile [55-68]. To our knowledge, seven patients out of the 14 reported developed severe respiratory failure requiring ICU admission and MV. However, it was unclear if the cause of respiratory failure was due to GBS or the severity of the respiratory infection.

Toscano et al. [56] rose a very important point, as whether the reduced vital capacity (VC) in their patients was proportional to neuromuscular weakness and to the extent of the chest imaging findings; interestingly, three cases had normal thorax scans, whereas the other three revealed typical interstitial pneumonia. Table 1 summarizes the demographic characteristics of the reported patients: age, gender, delay between antecedent infections and neurological symptoms, cranial nerve involvement, clinical phenotypes, electrophysiological findings, CSF results, treatments and final outcome.

\section{Differential diagnosis in GBS related to COVID-19 infection}

CIP and CIM are complications of critical illness that are present in ICU patients with muscle weakness and weaning failure after ventilation [69]. Muscle weakness is frequent in ICU patients with a reported median prevalence of $43 \%$ (interquartile range $27-75 \%$ ) over 31 studies [69]. The need of a differential diagnosis between GBS and CIP or CIM was considered and discussed by Kim et al. [15] in four patients with MERS coronavirus infection. Indeed, from the clinical point of view, differential diagnosis is important for treatment strategy. The key points for differential diagnosis between ICU-acquired weakness and GBS during or after COVID-19 infection are the following: (1) the disease course is typically monophasic and the onset is rapid in GBS; (2) the history of exposure to neuromuscular blockade agents is crucial in the development of CIP and CIM, while it is not part of the pathogenetic mechanism of GBS; (3) cranial nerves are spared in CIP/CIM; (4) CSF in GBS might show albuminocytological dissociation; (5) in GBS the serum might exhibit antiganglioside antibodies.

\section{Consequences of GBS overlap in acute respiratory failure due to SARS-CoV-2}

SARS-CoV-2 is reported to cause acute highly lethal pneumonia in $15 \%$ of cases with clinical features similar to those reported for SARS-CoV and MERS-CoV, but with different phenotypes and heterogeneous presentation [1-3, 23, 24]. Indeed, the pathophysiological characteristics of patients with SARS-CoV-2 pneumonia may differ from what previously defined by the ARDS Berlin criteria [31]. Observational data document that more than $50 \%$ of cases exhibit a dissociation between the mechanical characteristics of the respiratory system and the severity of hypoxemia [33]; in these patients, the compliance of the respiratory system is almost within normal range $\left(>50 \mathrm{~mL} / \mathrm{cmH}_{2} \mathrm{O}\right)$, as well as the amount of gas in the lung, while presenting with a high shunt fraction (about 50\%). The mechanism underlying this discrepancy is not known, but severe hypoxemia can probably be explained by an altered regulation of perfusion due to the loss of hypoxic vasoconstriction [33, 34]. Autopsy and lung biopsy studies show that at least some SARS-CoV-2 infected patients who are critically ill present a generalized thrombotic microvascular injury mediated by intense complement activation [70]; these findings could justify the severe respiratory distress despite relatively normal respiratory mechanics.

Moreover, a proportion (30\%) of patients with SARSCoV-2 pneumonia may share clinical features and physiological characteristics with severe ARDS: severe hypoxemia, low respiratory system compliance $\left(<40 \mathrm{~mL} / \mathrm{cmH}_{2} \mathrm{O}\right)$ and diffuse bilateral infiltrates on CT scan. Based on these observations, Gattinoni et al. [35] proposed the distinction between two phenotypes of critically ill patients with SARSCoV-2 pneumonia: (1) "non-ARDS" type L (low elastance, low ventilation-to-perfusion, low lung weight, low lung recruitability), (2) "ARDS" type $\mathrm{H}$ (high elastance, high right-to-left shunt, high lung weight, high lung recruitability). In some cases, the two phenotypes could even represent 


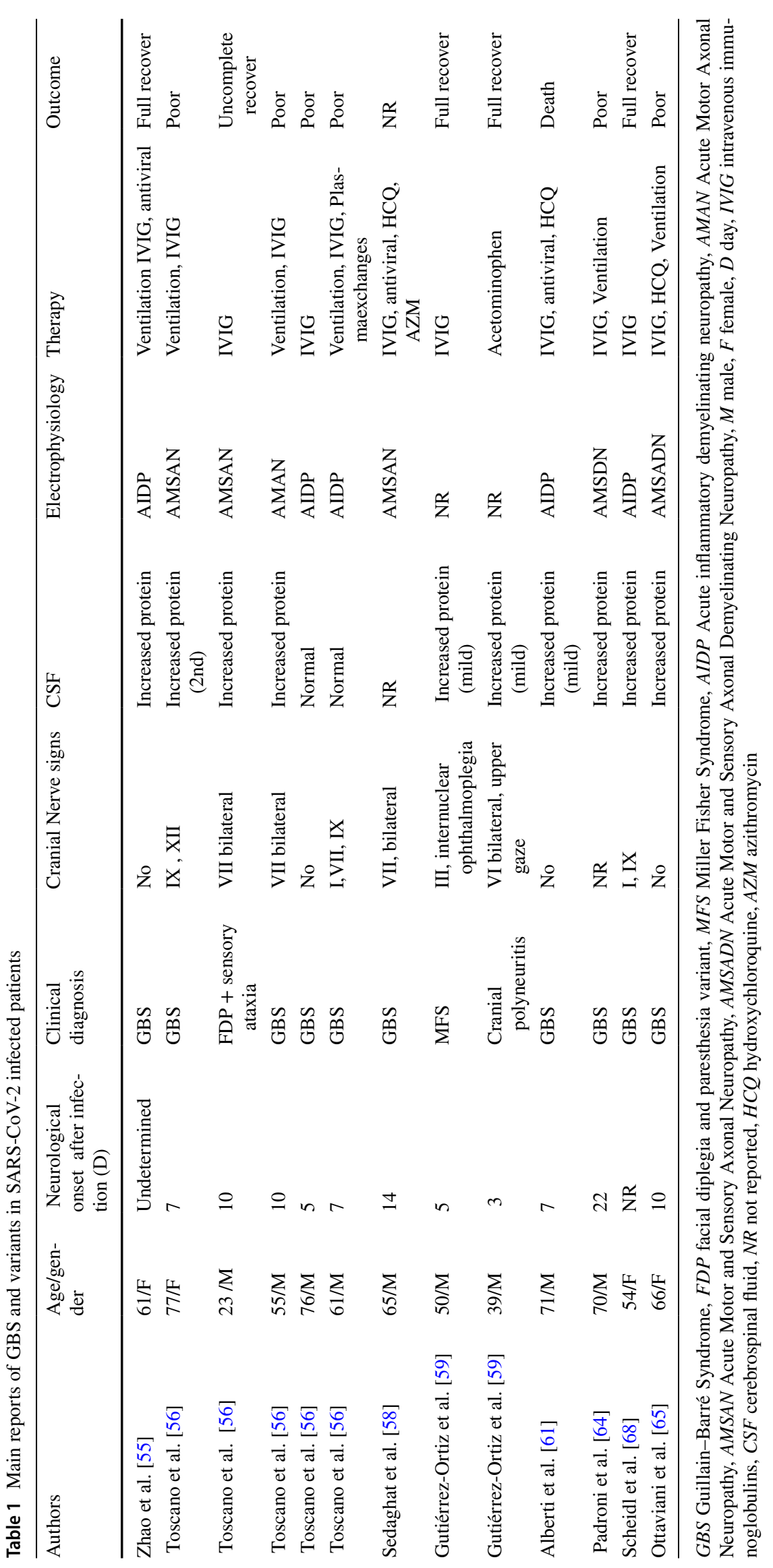




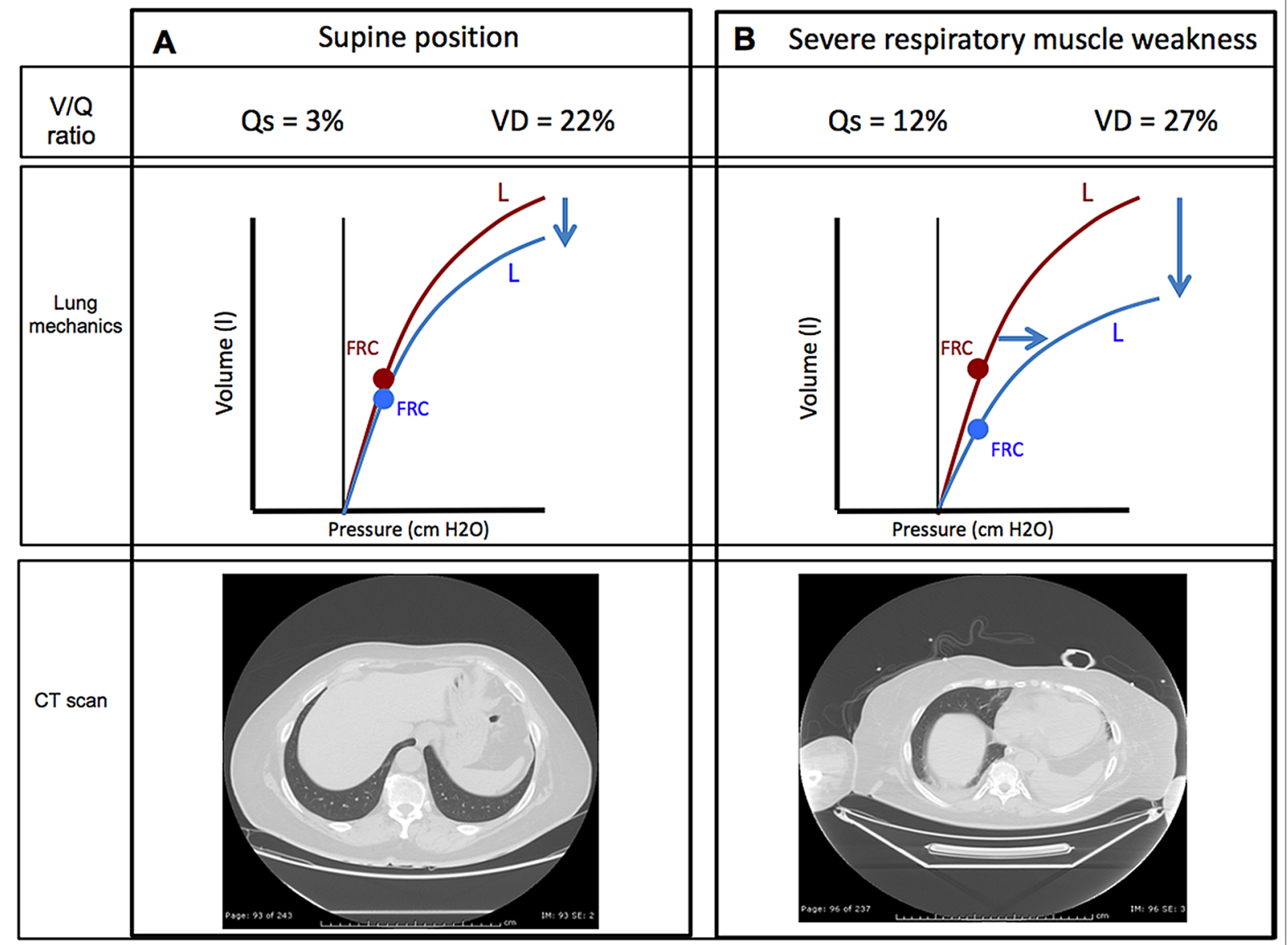

Fig. 1 Example of respiratory pathophysiological changes in a patient with GBS. The upper part of the figure estimate shunt fraction $\left(\mathrm{Q}_{\mathrm{S}}\right)$ and dead space (VD). The middle represents the pressure-volume relationship of the lung (red line: normal lung, blue line: effect of the supine position and respiratory muscle weakness). The lower part of the figure shows CT scan of the basal areas of the lung. Panel A 62-year-old GBS with intact respiratory muscle function. In supine position, there is a physiological slight decrease in FRC (see lung pressure-volume relationship). CT scan is normal. Panel B The patient develops severe diaphragmatic weakness with appearance of basal atelectasis at CT scan, decrease in compliance and significant increase in shunt fraction $\left(\mathrm{Q}_{\mathrm{S}}\right)$ two phases of the same disease; indeed, patients with type L may have a progression to type $\mathrm{H}$.

Pulmonary alterations may overlap with an acute neuromuscular disease such as GBS which can cause relevant respiratory physiological changes. Predictive factors for the development of respiratory failure are bulbar dysfunction, short interval between onset of weakness and hospital admission, high Erasmus GBS Respiratory Insufficiency Score (EGRIS 5-7 indicates high risk) [49]. The development of respiratory muscle weakness has obvious consequences on respiratory mechanics, ventilation-perfusion mismatch and gas exchange. Early studies on neuromuscular disorders showed a change in lung volumes by reporting decrease in vital capacity (VC), moderate reduction in functional residual capacity (FRC) and normal residual volume (RV) [71]. The reduction in VC was initially attributed to the direct effect of weakness of inspiratory and expiratory muscles, but subsequent observations have shown that the elastic properties of the lung were altered with a significant reduction in compliance $[72,73]$. Reduced lung distensibility was attributed to loss of gas-containing alveoli (patchy atelectasis), generalized increase in surface tension of the alveolar lining layer caused by breathing at low lung volume, and intrinsic alteration in lung tissue elasticity.

In patients with GBS, the rapid development of severe diaphragmatic weakness can lead to the appearance of areas of basal atelectasis causing a reduction in lung compliance and an increase in the intrapulmonary shunt (Fig. 1). These changes, in association with COVID-19 pneumonia, can cause rapid worsening of respiratory mechanics and hypoxemia, with the appearance of alveolar hypoventilation and hypercapnia. Given that, from a 
clinical point of view, the alarming respiratory markers suggesting an overlap between SARS-CoV-2 pneumonia and a neuromuscular disorder affecting respiratory muscle such as GBS are the appearance of hypercapnia and basal atelectasis. Therefore, in patients with SARS-CoV-2 infection, when the diagnosis of GBS has been established or even suspected, respiratory muscle assessment is clinically essential to decide the timing of tracheal intubation. A VC of less than $20 \mathrm{~mL} / \mathrm{kg}$, maximal inspiratory pressure (MIP) less than $-30 \mathrm{cmH}_{2} \mathrm{O}$, maximal expiratory pressure less than $40 \mathrm{cmH}_{2} \mathrm{O}$ or a decrease of $\mathrm{VC}$ greater than $30 \%$ over $24 \mathrm{~h}$, are good indicators of the need for invasive MV [25].

\section{Conclusions}

Since WHO declared COVID-19 as a "Public Health Emergency of International Concern" on January 30, 2020, all the neurologists' work has changed. Now, almost 4 months from the pandemic spread, the impact of COVID-19 on neurological care and patient services is relevant. Joint efforts are essential to gather the needed clinical data to develop awareness, recognition of clinical manifestations and specific treatment guidelines. For patients with COVID-19, much is still unknown about clinical and neurological complications (i.e., their frequency, characteristics, pathophysiology, risk factors, and prognosis) and possible regional differences in the disease course and outcomes [75, 76].

To conclude, it is unproven up to now whether COVID19 is able to trigger or it is simply accidentally associated with GBS. Further investigations, large trials and case control studies should be conducted to clarify their association and possible causality. Post-infectious molecular mimicry plays a crucial role in GBS, but it has been proven only in animal models for $C$. jejuni infection and not for other preceding viral infections; therefore, it might be unlikely as mechanism of SARS-CoV-2 related GBS. Given that, we must take into account some seminal works on viral mimicry in severe SARS respiratory syndrome involving the binding of virus antibody complexes to $\mathrm{Fc}$ or complement receptors on the surface of monocytes or macrophages resulting in virus uptake via receptor mediated endocytosis [74].

Another issue to be discussed concerns the timing of onset of neurological signs in relation with the viral infection. In some patients, neurologic symptoms appeared as early as few days after, suggesting a direct viral neuropathic mechanism progressing with a hyperacute parainfectious temporal profile $[55,61,65]$. In this context, also intrinsic host factors (i.e., genetic susceptibility) may play a role in the magnitude of the "cytokine storm" during the early phases of the disease.
Moreover, we wish to add a few practical comments which might help clinicians. First, the diagnosis of GBS must be considered in patients with COVID-19 who develop signs of diaphragmatic weakness (basal atelectasis on chest X-ray, development of hypercapnia in arterial blood gas analysis). Second, in patients with suspected or diagnosed acute neuromuscular disease in the course of COVID-19 infection, the instrumental monitoring of the respiratory muscles is recommended in addition to a careful neurological evaluation and it is critical in deciding the timing of intubation regardless of the degree of respiratory failure from SARS-CoV-2 infection. Finally, in ICU patients with COVID-19 infection, the development of diaphragmatic weakness is not uncommon, therefore, a careful differential diagnosis between ICU-acquired weakness and GBS should be taken into consideration, since the two conditions require different therapeutic strategies.

\section{Compliance with ethical standards}

Conflict of interest The authors declare that they have no conflict of interest.

Ethical approval "This article does not contain any studies with human participants or animals performed by any of the authors."

Informed consent "Informed consent was obtained from all individual participants included in the study."

\section{References}

1. Cao Y, Liu X, Xiong L, Cai K (2020) Imaging and clinical features of patients with 2019 novel coronavirus SARS-CoV-2: a systematic review and meta-analysis. J Med Virol. https://doi. org/10.1002/jmv.25822

2. Huang C, Wang Y, Li X et al (2020) Clinical features of patients infected with 2019 novel coronavirus in Wuhan. China Lancet 395(10223):497-506. https://doi.org/10.1016/S0140 $-6736(20) 30183-5$

3. Guan W-J, Ni Z-Y, Hu Y et al (2020) Clinical characteristics of coronavirus disease 2019 in China. N Engl J Med 382(18):17081720. https://doi.org/10.1056/NEJMoa2002032

4. Chen G, Wu D, Guo W et al (2020) Clinical and immunological features of severe and moderate coronavirus disease 2019. J Clin Invest 130(5):2620-2629. https://doi.org/10.1172/JCI137244

5. Wu C, Chen X, Cai Y et al (2020) Risk factors associated with acute respiratory distress syndrome and death in patients with coronavirus disease 2019 pneumonia in Wuhan. JAMA Intern Med, China, e200994. https://doi.org/10.1001/jamaintern med.2020.0994

6. Zhang J, Wang X, Jia X et al (2020) Risk factors for disease severity, unimprovement, and mortality in COVID-19 patients in Wuhan China. Clin Microbiol Infect 26(6):767-772. https://doi. org/10.1016/j.cmi.2020.04.012

7. Holshue ML, DeBolt C, Lindquist S et al (2020) First case of 2019 novel coronavirus in the United States. N Engl J Med 382(10):929-936. https://doi.org/10.1056/NEJMoa200119 
8. Diaz JH (2020) Hypothesis: angiotensin-converting enzyme inhibitors and angiotensin receptor blockers may increase the risk of severe COVID-19. J Travel Med 27(3):041. https://doi. org/10.1093/jtm/taaa041

9. Hamming I, Timens W, Bulthuis ML et al (2004) Tissue distribution of ACE2 protein, the functional receptor for SARS coronavirus. A first step in understanding SARS pathogenesis. J Pathol 203:631-637. https://doi.org/10.1002/path.1570

10. Saad M, Omrani AS, Baig K et al (2014) Clinical aspects and outcomes of 70 patients with middle East respiratory syndrome coronavirus infection: a single-center experience in Saudi Arabia. Int J Infect Dis 29:301-306. https://doi.org/10.1016/j.ijid.2014.09.003

11. Zhou Y, Han T, Chen J et al (2020) Clinical and autoimmune characteristics of severe and critical cases with COVID-19. Clin Transl Sci. https://doi.org/10.1111/cts.12805

12. Wang L, He W, Yu X et al (2020) Coronavirus disease 2019 in elderly patients: Characteristics and prognostic factors based on 4-week follow-up. J Infect 80(6):639-645. https://doi. org/10.1016/j.jinf.2020.03.019

13. Liu Y, Mao B, Liang S et al (2020) Association between ages and clinical characteristics and outcomes of coronavirus disease 2019. Eur Respir J 55(5):200111. https://doi.org/10.1183/13993 003.01112-2020

14. Li Y-C, Bai W-Z, Hashikawa T (2020) The neuroinvasive potential of SARS-CoV2 may play a role in the respiratory failure of COVID-19 patients. J Med Virol. 92(6):552-555. https://doi. org/10.1002/jmv. 25728

15. Kim JE, Heo JH, Kim HO et al (2017) Neurological complications during treatment of middle east respiratory syndrome. J Clin Neurol 13:227-233. https://doi.org/10.3988/jen.2017.13.3.227

16. Arabi YM, Harthi A, Hussein J et al (2015) Severe neurologic syndrome associated with Middle East respiratory syndrome corona virus (MERS-CoV). Infection 43:495-501. https://doi. org/10.1007/s15010-015-0720-y

17. Wu Y, Xu X, Chen Z et al (2020) Nervous system involvement after infection with COVID-19 and other coronaviruses. Brain Behav Immun 1591(87):18-22. https://doi.org/10.1016/j. bbi.2020.03.031

18. Yin R, Feng W, Wang T et al (2020) Concomitant neurological symptoms observed in a patient diagnosed with coronavirus disease 2019. J Med Virol. https://doi.org/10.1002/jmv.25888

19. Mao L, Jin H, Wang M et al (2020) Neurologic manifestations of hospitalized patients with coronavirus disease 2019 in Wuhan. JAMA Neurol 77(6):1-9. https://doi.org/10.1001/jamaneurol .2020 .1127

20. Asadi-Pooya AA, Simani L (2020) Central nervous system manifestations of COVID-19: a systematic review. J Neurol Sci 413:116832. https://doi.org/10.1016/j.jns.2020.116832

21. Roe K (2020) Explanation for COVID-19 infection neurological damage and reactivations. Transbound Emerg Dis. https://doi. org/10.1111/tbed.13594

22. Yashavantha Rao HC, Jayabaskaran C (2020) The emergence of a novel coronavirus (SARS-CoV-2) disease and their neuroinvasive propensity may affect in COVID-19 patients. J Med Virol 92(7):786-790. https://doi.org/10.1002/jmv.25918

23. Bertran Recasens B, Martinez-Llorens JM, Rodriguez-Sevilla JJ, Rubio MA (2020) Lack of dyspnea in Covid-19 patients; another neurological conundrum? Eur J Neurol. https://doi.org/10.1111/ ene. 14265

24. Shi H, Han X, Jiang $N$ et al (2020) Radiological findings from 81 patients with covid-19 pneumonia in wuhan, china: a descriptive study. Lancet Infect Dis 20(4):425-434. https://doi.org/10.1016/ S1473-3099(20)30086-4

25. Hocker S (2017) Primary acute neuromuscular respiratory failure. Neurol Clin 35(04):707-721. https://doi.org/10.1016/j. ncl.2017.06.007
26. Guidon AC, Amato AA (2020) COVID-19 and neuromuscular disorders. Neurology 94(22):959-969. https://doi.org/10.1212/ WNL.0000000000009566

27. Rajaballyb YA, Goedee HS, Attarian S, Hartung H (2020) Management challenges for chronic dysimmune neuropathies during the COVID-19 pandemic. Muscle Nerve. 62(1):34-40. https://doi. org/10.1002/mus.26896

28. Manji H, Carr AS, Brownlee WJ, Lunn MP (2020) Neurology in the time of covid-19. J Neurol Neurosurg Psychiatry 56:570. https ://doi.org/10.1136/jnnp-2020-323414

29. Sellner J, Taba P, Oztürk S, Helbok R (2020) The need for neurologists in the care of COVID-19 patients. Eur J Neurol. https:// doi.org/10.1111/ene.14257

30. International MG/COVID - 19 working group, Jacob S, Muppidi S et al (2020) Guidance for the management of myasthenia gravis (MG) and Lambert-Eaton myasthenic syndrome (LEMS) during the COVID-19 pandemic. J Neurol Sci 412:116803. https://doi. org/10.1016/j.jns.2020.116803

31. ARDS Definition Task force, Ranieri VM, Rubenfeld GD et al (2012) Acute respiratory distress syndrome: the Berlin definition. JAMA 307:2526-2533. https://doi.org/10.1001/jama.2012.5669

32. Gattinoni L, Chiumello D, Caironi P et al (2020) COVID-19 pneumonia different respiratory treatments for different phenotypes. Intensive Care Med 46(6):1099-1102. https://doi.org/10.1007/ s00134-020-06033-2

33. Gattinoni L, Coppola S, Cressoni M et al (2020) Covid-19 does not lead to a "Typical" acute respiratory distress syndrome. Am J Respir Crit Care Med 201(10):1299-1300. https://doi. org/10.1164/rccm.202003-0817LE

34. Salehi S, Abedi A, Balakrishnan S, Gholamrezanezhad A (2020) Coronavirus disease 2019 (COVID-19) a systematic review of imaging findings in 919 patients. AJR Am J Roentgenol 14:1-7. https://doi.org/10.2214/AJR.20.23034

35. Gattinoni L, Chiumello D, Rossi S (2020) COVID-19 pneumonia: ARDS or not. Crit Care 24:154. https://doi.org/10.1186/s1305 4-020-02880-z

36. Wakerley BR, Uncini A, Yuki N (2014) Guillain-Barré and miller fisher syndromes - new diagnostic classification. Nat Rev Neurol 10:537-544. https://doi.org/10.1038/nrneurol.2014.138

37. Wakerley BR, Yuki N (2014) Pharyngeal-cervical-brachial variant of Guillain-Barré syndrome. J Neurol Neurosurg Psychiatry 85:339-344. https://doi.org/10.1136/jnnp-2013-305397

38. Fokke C, van den Berg B, Drenthen J et al (2014) Diagnosis of Guillain-Barré syndrome and validation of Brighton criteria. Brain 137:33-43. https://doi.org/10.1093/brain/awt285

39. Hughes RAC, Cornblath DR, Willison HJ (2016) Guillain-Barré syndrome in the 100 years since its description by Guillain, Barré and Strohl. Brain 139:3041-3047. https://doi.org/10.1093/brain/ aww247

40. Leonhard SE, Mandarakas MR, Gondim FAA et al (2019) Diagnosis and management of Guillain-Barré syndrome in ten steps. Nat Rev Neurol 15:671-683. https://doi.org/10.1038/s4158 2-019-0250-9

41. Willison HJ, Jacobs BC, van Doorn PA (2016) Guillain-Barre' syndrome. Lancet 388:717-727. https://doi.org/10.1016/S0140 -6736(16)00339-1

42. Doets AY, Verboon C, van den Berg B et al (2018) Regional variation of Guillain-Barré syndrome. Brain 141:2866-2877. https:// doi.org/10.1093/brain/awy232

43. Verboon C, Doets AY, Galassi G et al (2019) Current treatment practice of Guillain-Barré syndrome. Neurology 93:e59-e76. https://doi.org/10.1212/WNL.0000000000007719

44. Yuki N, Yamada M, Koga M et al (2001) Animal model of axonal Guillain-Barré syndrome induced by sensitization with GM1 ganglioside. Ann Neurol 49:712-720. https://doi.org/10.1002/ ana.1012 
45. Zhang M, Gilbert M, Yuki N et al (2015) Association of antiGT1a antibodies with an outbreak of Guillain-Barré syndrome and analysis of ganglioside mimicry in an associated campylobacter jejuni strain. PLoS ONE 10:e0131730. https://doi.org/10.1371/ journal.pone. 0131730

46. Hao Y, Wang W, Jacobs BC et al (2019) Antecedent infections in Guillain-Barré syndrome: a single-center, prospective study. Ann Clin Transl Neurol 6:2510-2517. https://doi.org/10.1002/ acn3.50946

47. Ebrahim Soltani Z, Rahmani F, Rezaei N (2019) Autoimmunity and cytokines in Guillain-Barré syndrome revisited: review of pathomechanisms with an eye on therapeutic options. Eur Cytokine Netw 30(1):1-14. https://doi.org/10.1684/ecn.2019.0424

48. Islam Z, Papri N, Ara G et al (2019) Risk factors for respiratory failure in Guillain-Barré syndrome in Bangladesh: a prospective study. Ann Clin Transl Neurol 6(2):324-332. https://doi. org/10.1002/acn3.706

49. Walgaard C, Lingsma HF, Ruts L et al (2010) Prediction of respiratory insufficiency in Guillain-Barré syndrome. Ann Neurol 67:781-787. https://doi.org/10.1002/ana.21976

50. Parra B, Lizarazo J, Jiménez-Arango JA et al (2016) GuillainBarré syndrome associated with Zika virus infection in Colombia. N Engl J Med 375:1513-1523. https://doi.org/10.1056/NEJMo a1605564

51. Frontera JA, da Silva IR (2016) Zika getting on your nerves? The association with the Guillain-Barré Syndrome. N Engl J Med 375(16):1581-1582. https://doi.org/10.1056/NEJMe1611840

52. Lucchese G, Kanduc D, Lucchese G et al (2016) Zika virus and autoimmunity: From microcephaly to Guillain-Barré syndrome, and beyond. Autoimmun Rev 15:801-808. https://doi. org/10.1016/j.autrev.2016.03.020

53. Tsai LK, Hsieh ST, Chao CC et al (2004) Neuromuscular disorders in severe acute respiratory syndrome. Arch Neurol 61:16691673. https://doi.org/10.1001/archneur.61.11.1669

54. Beydon M, Chevalier K, Al Tabaa O et al (2020) Myositis as a manifestation of SARS-CoV-2. Ann Rheum Dis. https://doi. org/10.1136/annrheumdis-2020-217573

55. Zhao H, Shen D, Zhou H, Liu J, Chen S (2020) Guillain-Barré syndrome associated with SARS-CoV-2 infection: causality or coincidence? Lancet Neurol 19:383-384. https://doi.org/10.1016/ S1474-4422(20)30109-5

56. Toscano G, Palmerini F, Ravaglia S et al (2020) Guillain-Barré Syndrome associated with SARS-CoV-2. New Engl J Med. 382(26):2574-2576. https://doi.org/10.1056/NEJMc2009191

57. Virani A, Rabold E, Hanson T et al (2020) Guillain-Barré syndrome associated with SARS-CoV-2 infection. Idcases 20:e00771. https://doi.org/10.1016/j.idcr.2020.e00771

58. Sedaghat Z, Karimi N (2020) Guillain Barre syndrome associated with COVID-19 infection: a case report. J Clin Neurosci 76:233-235. https://doi.org/10.1016/j.jocn.2020.04.062

59. Gutiérrez-Ortiz C, Méndez A, Rodrigo-Rey S et al (2020) Miller Fisher Syndrome and polyneuritis cranialis in COVID-19. Neurology. https://doi.org/10.1212/WNL.0000000000009619

60. Dinkin M, Gao V, Kahan J et al (2020) COVID-19 presenting with ophthalmoparesis from cranial nerve palsy. Neurology. https://doi. org/10.1212/WNL.0000000000009700

61. Alberti P, Beretta S, Piatti M et al (2020) Guillain-Barré syndrome related to COVID-19 infection. Neurol Neuroimmunol Neuroinflamm 7(4):e741. https://doi.org/10.1212/NXI.000000000000074 1
62. El Otmani H, El Moutawakil B, Rafai M-A et al (2020) Covid19 and Guillain-Barré syndrome: more than a coincidence. Rev Neurol (Paris) 176(6):518-519. https://doi.org/10.1016/j.neuro 1.2020.04.007

63. Coen M, Jeanson G, Alejandro Culebras Almeida L et al (2020) Guillain-Barré syndrome as a complication of SARSCoV-2 infection. Brain Behav Immun 87:111-112. https://doi. org/10.1016/j.bbi.2020.04.074

64. Padroni M, Mastrangelo V, Asioli GM et al (2020) Guillain-Barré syndrome following COVID-19: new infection, old complication? J Neurol 267:1877-1879. https://doi.org/10.1007/s00415-02009849-6

65. Ottaviani D, Boso F, Tranquillini E et al (2020) Early GuillainBarré syndrome in coronavirus disease 2019 (COVID-19): a case report from an Italian COVID-hospital. Neurol Sci 41:1351-1354. https://doi.org/10.1007/s10072-020-04449-8

66. Juliao Caamaño DS, Alonso BR (2020) Facial diplegia, a possible atypical variant of Guillain-Barré syndrome as a rare neurological complication of SARS-CoV-2. J Clin Neurosci. 77:230-232. https ://doi.org/10.1016/j.jocn.2020.05.016

67. Chan JL, Ebadi H, Sarna JR (2020) Guillain-Barré syndrome with facial diplegia related to SARS-CoV-2 infection. Can J Neurol Sci 1:10. https://doi.org/10.1017/cjn.2020.106

68. Scheidl E, Canseco Diez D, Hadji-Naumov A, Bereznai J (2020) Guillain-Barré syndrome during SARS-CoV-2 pandemic: a case report and review of recent literature. J Peripher Nerv Syst 25(2):204-207. https://doi.org/10.1111/jns.12382

69. Vanhorebeek I, Latronico N, Van den Berghe G (2020) ICUacquired weakness. Intensive Care Med 25(2):204-207. https:// doi.org/10.1007/s00134-020-05944-4

70. Magro C, Mulvey JJ, Berlin D et al (2020) Complement associated microvascular injury and thrombosis in the pathogenesis of severe COVID-19 infection: a report of five cases. Trans1 Res 220:1-13. https://doi.org/10.1016/j.trs1.2020.04.007

71. Ferris BG Jr, Warren A, Beals CA (1955) The vital capacity as a measure of the spontaneous breathing ability in poliomyelitis. $\mathrm{N}$ Engl J Med 252:618-621. https://doi.org/10.1056/NEJM195504 142521504

72. De Troyer A, Borenstein S, Cordier R (1980) Analysis of lung volume restriction in patients with respiratory muscle weakness. Thorax 35:603-610. https://doi.org/10.1136/thx.35.8.603

73. Gibson GJ, Pride NB (1979) Pride NB (1979) Lung mechanic. Am Rev Respir Dis 11:119-120. https://doi.org/10.1164/ arrd.1979.119.2P2.119

74. Chew FT, Ong SY, Hew CL (2003) Severe acute respiratory syndrome coronavirus and viral mimicry. Lancet 361(9374):2081. https://doi.org/10.1016/s0140-6736(03)13652-723

75. The Lancet Neurology (2020) The Neurological impact of COVID-19. Lancet Neurol 19(6):471. https://doi.org/10.1016/ S1474-4422(20)30142-3

76. Dalakas MC (2020) Guillain-Barre' syndrome: the first documented CoVID-19-triggered autoimmune neurologic disease. Neurol Neuroimmunol Neuroinflamm 7:e781. https://doi. org/10.1212/NXI.0000000000000781

Publisher's Note Springer Nature remains neutral with regard to jurisdictional claims in published maps and institutional affiliations. 